\title{
Postoperative Increase in Occiput-C2 Angle Negatively Impacts Subaxial Lordosis after Occipito-Upper Cervical Posterior Fusion Surgery
}

\author{
Taigo Inada ${ }^{1}$, Takeo Furuya ${ }^{1}$, Koshiro Kamiya ${ }^{1}$, Mitsutoshi Ota ${ }^{1}$, Satoshi Maki ${ }^{1}$, Takane Suzuki ${ }^{2}$, \\ Kazuhisa Takahashi ${ }^{1}$, Masashi Yamazaki ${ }^{3}$, Masaaki Aramomi ${ }^{4}$, Chikato Mannoji ${ }^{4}$, Masao Koda ${ }^{1}$ \\ ${ }^{1}$ Department of Orthopedic Surgery, Graduate School of Medicine, Chiba University, Chiba, Japan \\ ${ }^{2}$ Department of Bioenvironmental Medicine, Graduate School of Medicine, Chiba University, Chiba, Japan \\ ${ }^{3}$ Department of Orthopedic Surgery, University of Tsukuba, Tsukuba, Japan \\ ${ }^{4}$ Department of Orthopedic Surgery, Teikyo University, Chiba Medical Center, Ichihara, Japan
}

Study Design: Retrospective case series.

Purpose: To elucidate the impact of postoperative occiput-C2 (0-C2) angle change on subaxial cervical alignment.

Overview of Literature: In the case of occipito-upper cervical fixation surgery, it is recommended that the $0-\mathrm{C} 2$ angle should be set larger than the preoperative value postoperatively.

Methods: The present study included 17 patients who underwent occipito-upper cervical spine (above C4) posterior fixation surgery for atlantoaxial subluxation of various etiologies. Plain lateral cervical radiographs in a neutral position at standing were obtained and the 0-C2 angle and subaxial lordosis angle (the angle between the endplates of the lowest instrumented vertebra (LIV) and C7 vertebrae) were measured preoperatively and postoperatively soon after surgery and ambulation and at the final follow-up visit.

Results: There was a significant negative correlation between the average postoperative alteration of $0-C 2$ angle (D0-C2) and the average postoperative alteration of subaxial lordosis angle (Dsubaxial lordosis angle) $(r=-0.47, p=0.03)$.

Conclusions: There was a negative correlation between DO-C2 and Dsubaxial lordosis angles. This suggests that decrease of midto lower-cervical lordosis acts as a compensatory mechanism for lordotic correction between the occiput and C2. In occipito-cervical fusion surgery, care must be taken to avoid excessive $0-\mathrm{C} 2$ angle correction because it might induce mid-to-lower cervical compensatory decrease of lordosis.

Keywords: Cervical spine; Occipital bone; Spinal curvatures; Spinal fusion

\section{Introduction}

Occipito-upper cervical posterior fusion surgery using an occipital plate and screw-rod system provides rigid and secure fixation for various kinds of lesions with clinical instabilities around the craniocervical junction [1]. In the case of occipito-upper cervical fixation surgery, caution should be paid to avoid an inadequate fixation angle between the occiput and upper cervical spine, because an inadequate angle can cause dysphagia and respiratory disturbance [2]. It is recommended that the occiput-C2 $(\mathrm{O}-\mathrm{C} 2)$ angle, which is the angle between the McGregor

Received Dec 3, 2015; Revised Jan 16, 2016; Accepted Jan 19, 2016

Corresponding author: Masao Koda

Department of Orthopedic Surgery, Chiba University Graduate School of Medicine,

1-8-1 Inohana, Chuo-Ku, Chiba 2608670, Japan

Tel: +81-43-226-2961, Fax: +81-43-224-5124, E-mail: masaokod@gmail.com 
line and the lower endplate of C2 vertebra, should be set larger than the preoperative value postoperatively. In other words, postoperative alignment between the occiput and upper cervical spine should be more lordotic to avoid dysphagia and respiratory disturbance [3]. It is not clear how the alteration of the $\mathrm{O}-\mathrm{C} 2$ angle affects subaxial cervical spine alignment.

The aim of the present study was to elucidate the impact of postoperative $\mathrm{O}-\mathrm{C} 2$ angle change on subaxial cervical alignment.

\section{Materials and Methods}

The present study included 17 patients who underwent occipito-upper cervical spine (above $\mathrm{C} 4$ ) posterior fixation surgery for atlantoaxial subluxation of various etiologies in our institute from May 2000 to November 2012. The present case series included 8 male and 9 female patients; the average age at surgery was 55.7-year-old (range, 16-84 years). The average follow-up period was 67.2 months (range, 5-126 months). The clinical diagnosis was upper cervical anomaly in 7 cases, rheumatoid arthritis in 4 cases, atlantoaxial subluxation in 4 cases, Down syndrome in 1 case, and pseudarthrosis after dens fracture in 1 case. The fusion level was $\mathrm{O}-\mathrm{C} 2$ in 8 cases, $\mathrm{O}-\mathrm{C} 3$ in 5 cases, and $\mathrm{O}-\mathrm{C} 4$ in 4 cases (Table 1 ). If the $\mathrm{C} 2$ pedicle screw could not insert because of high-riding vertebral artery or there was obvious osteoporosis, the fusion level was extended to caudally. Surgery was performed in the neutral position using a Mayfield skull cramp or Halovest. After insertion of screws and occiput plate, alignment was adjusted to extension position and the skull was sagittally rotated to obtain appropriate $\mathrm{O}-\mathrm{C} 2$ angle and upper cervical alignment.

Recovery rate (Hirabayashi) and change in Japanese Orthopedic Association (JOA) score were assessed as clinical outcome measures. Perioperative complications were assessed using clinical records.

Plain lateral cervical radiographs in a neutral position at standing were obtained and the $\mathrm{O}-\mathrm{C} 2$ and subaxial lordosis angles were measured preoperatively and postoperatively soon after surgery and ambulation and at the final follow-up visit. The $\mathrm{O}-\mathrm{C} 2$ angle was measured as the angle between the McGregor line and lower endplate of the $\mathrm{C} 2$ vertebra $[4,5]$. A positive value indicates lordosis between the occiput and $\mathrm{C} 2$, and a negative value indicates kyphosis between the occiput and C2. The sub-
Table 1. Patient background data

\begin{tabular}{lc} 
Variable & $\mathrm{n}=17$ \\
\hline Age at surgery (yr) & $55.7(16-84)$ \\
Sex (male:female) & $8: 9$ \\
\hline Diagnosis & \\
Upper cervical anomaly & 7 \\
\hline Rheumatoid arthritis & 4 \\
\hline Atlant-axial subluxation & 4 \\
\hline Down syndrome & 1 \\
\hline Dens fracture (pseudarthrosis) & 1 \\
\hline Fusion level & \\
\hline 0-C2 & 8 \\
\hline 0-C3 & 5 \\
\hline 0-C4 & 4 \\
\hline C2 0cciput-C2
\end{tabular}

0-C2, occiput-C2.

axial lordosis angle was defined as the angle between the endplates of the lowest instrumented vertebra (LIV) and C7 vertebrae, an indicator of cervical spine alignment. A positive value indicates lordosis between LIV and C7, and a negative value indicates kyphosis between LIV and C7. Change of the $\mathrm{O}-\mathrm{C} 2$ angle was defined as DO-C2 and change of the subaxial lordosis angle was defined as Dsubaxial lordosis. A positive value in $\mathrm{DO}-\mathrm{C} 2$ and Dsubaxial lordosis angles indicates increase of lordosis, and negative value in DO-C2 and Dsubaxial lordosis angles indicates decrease of lordosis. The cervical sagittal vertical axis (CSVA) was measured as the deviation of the center of gravity head-plumb line (extending from the anterior margin of the external auditory canal) from the posterior superior endplate of C7. T1 tilt was measured as the angle between the superior endplate of $\mathrm{T} 1$ and horizontal line $[4,5]$.

Preoperative and postoperative $\mathrm{O}-\mathrm{C} 2$ angle, subaxial lordosis angle, C-SVA, and T1 tilt at final follow-up were compared using a Tukey-Kramer honestly significant difference (HSD) test. DO-C2 and D subaxial lordosis angle correlation was determined using Pearson's correlation coefficient. A $p<0.05$ was considered significant.

\section{Results}

The average JOA score was 7.2 points preoperatively and 11.4 postoperatively, showing a change of 4.2 points and $43 \%$ recovery. Perioperative complications included postoperative reintubation in one case, cerebellum hemor- 
Table 2. Preoperative and postoperative radiographic parameters

\begin{tabular}{lccc} 
Variable & Preoperative & Postoperative & Change \\
\hline 0-C2 angle $\left(^{\circ}\right)$ & $1.8(-13.4$ to 20.1$)$ & $8.5(-4.6$ to 24.2$)$ & $6.7(-4.6$ to 24.2$)$ \\
\hline Subaxial lordosis $\left(^{\circ}\right)$ & $19.2(6.5$ to 32.9$)$ & $9.6(-15.9$ to 25.9$)$ & $-9.6(-22.4$ to 0$)$ \\
\hline C-SVA $(\mathrm{mm})$ & $6.3(-13.4$ to 20.1$)$ & $6.1(-4.6$ to 24.2$)$ & $-0.2(-13.9$ to 14.4$)$ \\
\hline T1 tilt $\left(^{\circ}\right)$ & $21.0(6.7$ to 33$)$ & $17.7(3$ to 34$)$ & $-3.1(-15$ to 7$)$ \\
\hline JOA score (point) & $7.5(3.5$ to 17$)$ & $12.7(8$ to 17$)$ & $5.2(0$ to 12.5$)$ \\
\hline
\end{tabular}

0-C2, occiput-C2; C-SVA, cervical sagittal vertical axis; JOA, Japanese Orthopedic Association.

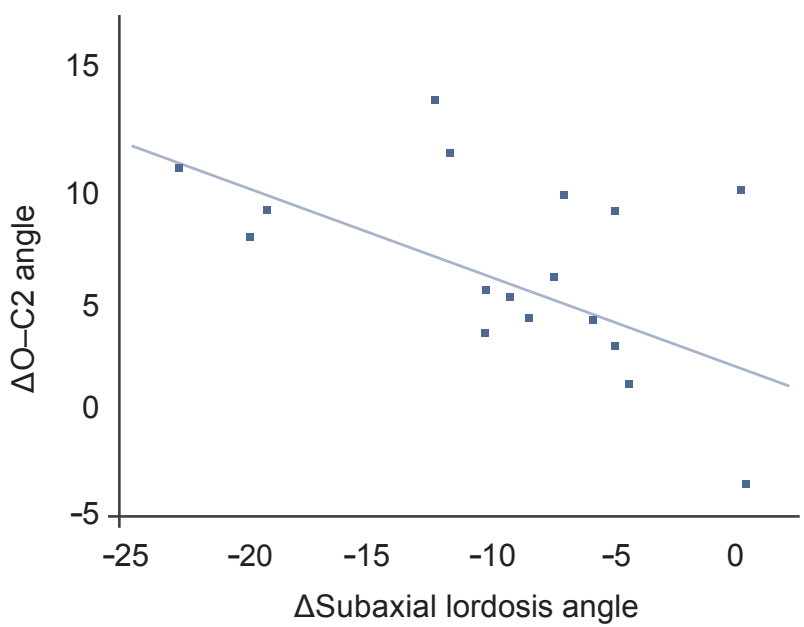

Fig. 1. Relationship between the change of the $0-C 2$ angle (DO-C2 angle) and change of the subaxial lordsis angle (Dsubaxial lordosis angle). There was a significant negative correlation between $\mathrm{DO}-\mathrm{C2}$ and Dsubaxial lordosis angles $(r=-0.47, p=0.03)$. 0-C2, occiput-C2.
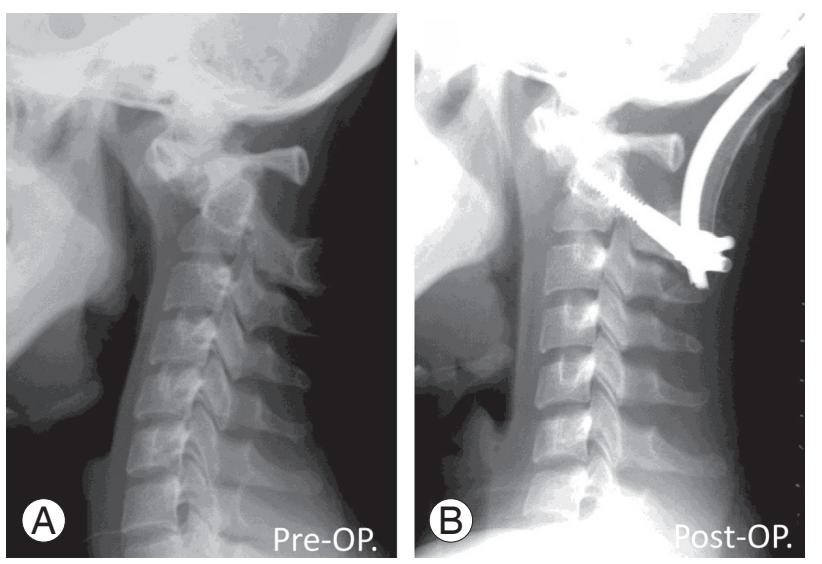

Fig. 2. Representative case involving a 17-year-old female with atlanto-axial subluxation due to Down's syndrome. Preoperative $X$-ray shows irreducible atlanto-axial subluxation (A). After 0-C2 fusion surgery, increase of $0-\mathrm{C} 2$ angle and decrease of subaxial lordosis was observed (B). $0-C 2$ angle was $-13^{\circ}$ preoperatively and $-2^{\circ}$ postoperatively. C2-7 angle was $9^{\circ}$ preoperatively and $-11^{\circ}$ postoperatively. 0 C2, occiput-C2; Pre-OP, preoperative; Post-OP, postoperative. rhage in 1 case, and dysphagia in 2 cases.

There was significant difference between preoperative and postoperative subaxial lordosis angle, and postoperative and final follow-up subaxial lordosis angle $(p=0.04$, respectively) (Table 2 ). The average DO-C2 angle was $6.7^{\circ} \pm 4.0^{\circ}$ and the average Dsubaxial lordosis angle was $-9.5^{\circ} \pm 6.4^{\circ}$. There was a significant negative correlation between DO-C2 and Dsubaxial lordosis angles $(r=-0.47$, $p=0.03$ ) (Figs. 1, 2).

The average C-SVA was $6.3 \pm 14.3 \mathrm{~mm}$ preoperatively, $6.1 \pm 12.6 \mathrm{~mm}$ postoperatively and $7.2 \pm 11 \mathrm{~mm}$ at final follow-up. The average T1 tilt was $21.0^{\circ} \pm 7.1^{\circ}$ preoperatively, $17.7^{\circ} \pm 7.5^{\circ}$ postoperatively, and $19.7^{\circ} \pm 10.4^{\circ}$ at final followup visit. There was no significant difference between preoperative, postoperative, and final follow-up C-SVA and T1 tilt (Table 2).

\section{Discussion}

The present results demonstrate a negative correlation between DO-C2 and Dsubaxial lordosis angles. This suggests that decrease of mid- to lower-cervical lordosis acts as a compensatory mechanism for lordotic correction between the occiput and C2. This compensatory alignment change occurred immediately after ambulation and was maintained for follow-up. To avoid dysphagia, it is strongly recommended to fuse the occiput-cervical spine in a lordotic alignment, in which the $\mathrm{O}-\mathrm{C} 2$ angle is more positive than preoperatively [2].

There is a compensatory mechanism for spinal sagittal deformity to maintain horizontal gaze. For example, deformity of the thoracolumbar spine can induce cervical deformity [6]. Patients with a positive sagittal malalignment tend to compensate with abnormal cervical hyperlordosis to maintain a horizontal gaze, and surgical correction of the thoracolumbar sagittal malalignment results 
in attenuation of the cervical hyperlordosis via reciprocal change [7]. This spontaneous correction of cervical deformity after correction of global sagittal balance by lumbar pedicle subtraction osteotomy has been reported [8]. Corrective fusion surgery for marked cervical kyphosis results in attenuation of compensatory hyperlordosis of the thoracolumbar spine [9]. The present results are consistent with those compensatory mechanisms.

Incidentally, T1 tilt showed no apparent change after occipitocervical fusion surgery in the present case series. Presently, there was no significant change in C-SVA after surgery. These lines of evidence suggest that an increase in the $\mathrm{O}-\mathrm{C} 2$ angle had no significant impact on the sagittal balance of the thoracolumbar spine and the compensatory mechanism for O-C2 angle change within the cervical spine. Guo et al. [10] reported negative correlation between $\mathrm{O}-\mathrm{C} 2$ angle and $\mathrm{C} 2-7$ angle in asymptomatic population. Passias et al. [11] reported that $\mathrm{O}-\mathrm{C} 2$ angle and subaxial lordosis angle negatively correlated preoperatively and postoperatively. Those previous reports showed that the compensatory mechanism between occiput-upper cervical region and aubaxial cervical spine.

In occipitocervical fusion surgery, care must be taken to avoid excessive $\mathrm{O}-\mathrm{C} 2$ angle correction because it might induce mid-to-lower cervical compensatory decrease of lordosis. If there is preoperative kyphosis or anterior slip in the mid-to-lower cervical spine, excessive correction of the $\mathrm{O}-\mathrm{C} 2$ angle (hyperlordosis) might lead to deterioration of mid-to-lower cervical spine alignment [12]. In the case of occipitocervical fusion in combination with cervical laminoplasty, postoperative mid-to-lower cervical alignment prediction is important because lordosis is essential for spinal cord decompression by laminoplasty. Therefore, excessive correction of the $\mathrm{O}-\mathrm{C} 2$ angle might be avoided in such cases. Optimal correction of the $\mathrm{O}-\mathrm{C} 2$ angle remains unclear. Further exploration is needed to clarify this issue.

\section{Conclusions}

Change of $\mathrm{O}-\mathrm{C} 2$ angle negatively correlates with change of subaxial cervical lordosis in occipitocervical fusion surgery.

\section{Conflict of Interest}

No potential conflict of interest relevant to this article was reported.

\section{References}

1. Garrido BJ, Sasso RC. Occipitocervical fusion. Orthop Clin North Am 2012;43:1-9.

2. Miyata $M$, Neo M, Fujibayashi S, Ito $H$, Takemoto $M$, Nakamura T. O-C2 angle as a predictor of dyspnea and/or dysphagia after occipitocervical fusion. Spine (Phila Pa 1976) 2009;34:184-8.

3. Izeki M, Neo M, Takemoto M, et al. The O-C2 angle established at occipito-cervical fusion dictates the patient's destiny in terms of postoperative dyspnea and/ or dysphagia. Eur Spine J 2014;23:328-36.

4. Ames CP, Blondel B, Scheer JK, et al. Cervical radiographical alignment: comprehensive assessment techniques and potential importance in cervical myelopathy. Spine (Phila Pa 1976) 2013;38(22 Suppl 1):S149-60.

5. Scheer JK, Tang JA, Smith JS, et al. Cervical spine alignment, sagittal deformity, and clinical implications: a review. J Neurosurg Spine 2013;19:141-59.

6. Smith JS, Lafage V, Schwab FJ, et al. Prevalence and type of cervical deformity among 470 adults with thoracolumbar deformity. Spine (Phila Pa 1976) 2014;39:E1001-9.

7. Smith JS, Shaffrey CI, Lafage V, et al. Spontaneous improvement of cervical alignment after correction of global sagittal balance following pedicle subtraction osteotomy. J Neurosurg Spine 2012;17:300-7.

8. Obeid I, Boniello A, Boissiere L, et al. Cervical spine alignment following lumbar pedicle subtraction osteotomy for sagittal imbalance. Eur Spine J 2015;24: 1191-8.

9. Koda M, Furuya T, Inada T, et al. Resolution of low back symptoms after corrective surgery for droppedhead syndrome: a report of two mcases. BMC Res Notes 2015;8:545.

10. Guo Q, Ni B, Yang J, Liu K, Sun Z, Zhou F, Zhang J. Relation between alignments of upper and subaxial cervical spine: a radiological study. Arch Orthop Trauma Surg 2011;131:857-62.

11. Passias PG, Wang S, Kozanek M, Wang S, Wang C. Relationship between the alignment of the occipitoaxial and subaxial cervical spine in patients with congenital atlantoxial dislocations. J Spinal Disord Tech 2013;26:15-21.

12. Matsunaga S, Onishi T, Sakou T. Significance of occipitoaxial angle in subaxial lesion after occipitocervical fusion. Spine (Phila Pa 1976) 2001;26:161-5. 